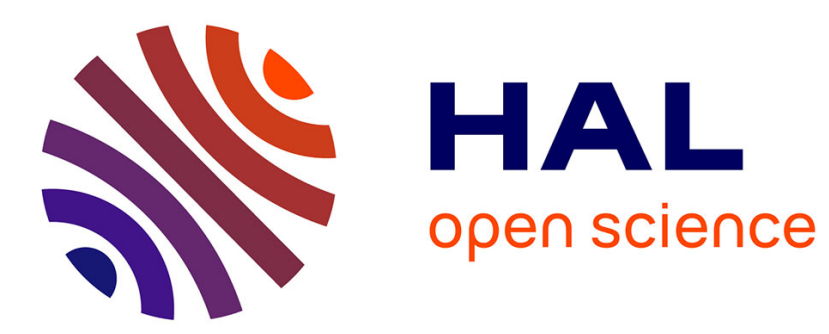

\title{
Acoustoplastic Effect and Amplitude-Dependent Internal Friction During Deformation of Impure Aluminium Single Crystals
}

K. Sapozhnikov, S. Kustov

\section{- To cite this version:}

K. Sapozhnikov, S. Kustov. Acoustoplastic Effect and Amplitude-Dependent Internal Friction During Deformation of Impure Aluminium Single Crystals. Journal de Physique IV Proceedings, 1996, 06 (C8), pp.C8-293-C8-296. 10.1051/jp4:1996863 . jpa-00254671

HAL Id: jpa-00254671

https://hal.science/jpa-00254671

Submitted on 1 Jan 1996

HAL is a multi-disciplinary open access archive for the deposit and dissemination of scientific research documents, whether they are published or not. The documents may come from teaching and research institutions in France or abroad, or from public or private research centers.
L'archive ouverte pluridisciplinaire $\mathbf{H A L}$, est destinée au dépôt et à la diffusion de documents scientifiques de niveau recherche, publiés ou non, émanant des établissements d'enseignement et de recherche français ou étrangers, des laboratoires publics ou privés. 


\title{
Acoustoplastic Effect and Amplitude-Dependent Internal Friction During Deformation of Impure Aluminium Single Crystals
}

\author{
K.V. Sapozhnikov and S.B. Kustov \\ A.F. Ioffe Physical-Technical Institute, Russian Academy of Sciences, Politekhnicheskaya 26, \\ St. Petersburg 194021, Russia
}

\begin{abstract}
Time, temperature, plastic strain, strain rate and oscillatory stress amplitude dependences of the acoustoplastic effect and dislocation amplitude-dependent absorption of ultrasound causing this effect have been studied during three-point bending of aluminium single crystals. The acoustoplastic effect was observed not only during macroplastic deformation, but during microplastic deformation on "elastic" loading and during strain recovery on unloading as well. The time dependence of the acoustoplastic effect shows two components: "fast" (time-independent) and "slow" (time-dependent). Data obtained evidence for the distinction in defect structure levels responsible for the acoustoplastic effect and amplitude-dependent internal friction. Dislocation - dislocation interaction is suggested as a basic source of the acoustoplastic effect. Dislocation - point defect interaction plays a secondary part in mechanism of the acoustoplastic effect, even in case of dynamic strain ageing.
\end{abstract}

\section{INTRODUCTION}

The acoustoplastic effect (APE) appears as an acceleration of creep or as a decrease in flow stress during active deformation when an oscillatory component is superimposed on a static mechanical load. The decrease in flow stress $\Delta \sigma$ is caused by an additional plastic deformation $\Delta \varepsilon_{p}$ of a specimen, and $\Delta \sigma \propto$ $\Delta \varepsilon_{\mathrm{p}}$, since the specimen is unloaded elastically. Theoretical models of the APE [1-3] are based on stress superposition principle and equations of thermally-activated plasticity. However, according to experimental studies of the effect of temperature and impurity content on the APE [4-6], neither the stress superposition principle nor the equations of thermally-activated plasticity are suited for the theoretical description of the APE at least in ultrasonic frequency range. Mechanical activation of irreversible dislocation movement through long-range internal stress fields (dislocation-dislocation interaction) was suggested as a basic APE mechanism. Measurements of the amplitude dependences of damping of the vibrations causing the APE provide an information about APE mechanisms.

\section{EXPERIMENTAL DETAILS}

A computer-controlled setup based on three-component piezoelectric oscillator technique was used to excite the vibrations of samples with frequency of about $100 \mathrm{kHz}$ and to measure the amplitudedependent internal friction (ADIF). The APE and ADIF were simultaneously registered during three-point bending of the samples measured three half-wave lengths of ultrasound in length (approx. $72 \mathrm{~mm}$ ). The loading points were coincident with the vibration nodes of standing wave. The samples were deformed by a hydraulic testing machine "Instron 1341 " at a constant crosshead movement rate. The samples were cut from a rod-shaped square $(3 \times 3 \mathrm{~mm}) \mathrm{Al}$ single crystal of about $99.8 \%$ purity grown with [100] orientation by Stepanov's technique [7]. The basic impurities were $0.13 \mathrm{wt} \% \mathrm{Si}$ and $0.05 \mathrm{wt} . \% \mathrm{Fe}$.

The magnitude of deforming load decrease $\Delta \mathrm{P}$ was used as a measure of APE since the inhomogeneous stress took place during three-point bending. The additional plastic sag $\Delta \mathrm{d}$ of a specimen under central fixture gives rise to the elastic unloading [8]: $\Delta P=48 \mathrm{E} \mathrm{J} \Delta \mathrm{d} / \mathrm{s}^{3}$, where $\mathrm{E}$ is the elastic modulus, $J$ the inertia moment of the specimen's cross section, and $s$ the span between the lower 
deforming fixtures. Therefore, to obtain the temperature dependence of $\Delta \mathrm{d}$, the temperature dependence of $\Delta P$ should be normalized to that of the elastic modulus: $\Delta d(T) \propto \Delta P(T) E_{100} / E_{100}(T)$.

The oscillatory strain amplitude dependences of the APE and internal friction were measured at different deformation stages, temperatures and crosshead movement rates. In so doing, the oscillatory strain amplitude was first increased with a preset step from a low amplitude-independent level to a maximum value and then decreased in reverse sequence. The time to measure an amplitude dependence of the APE and ADIF (forward and reverse run) was about 1-2 min. The APE time dependences at constant oscillatory strain amplitudes were measured as well.

\section{RESULTS AND DISCUSSION}

Figure 1 shows deformation curve for an Al sample (a) along with the values of APE magnitude and ADIF at fixed level of oscillatory stress amplitude $\sigma_{m}(b)$. The evolution of stress amplitude dependences of the APE magnitude is depicted in Fig.2. The APE is observed not only during macroscopic plastic deformation, but during microplastic deformation as well. The sign of the effect reverses on unloading: the applied load rises during superimposition of vibrations when it is diminished to certain level lower than yield load. Both ADIF and APE show maxima during loading. The dependence of the APE on plastic strain passes through a maximum at yield point, whereas the ADIF maximum takes place well in the plastic range. The APE magnitude increases drastically as the yield point is approached and decreases with macroplastic strain rather slightly, but long-term insonation with high $\sigma_{m}$ appears to diminish the APE magnitude appreciably.

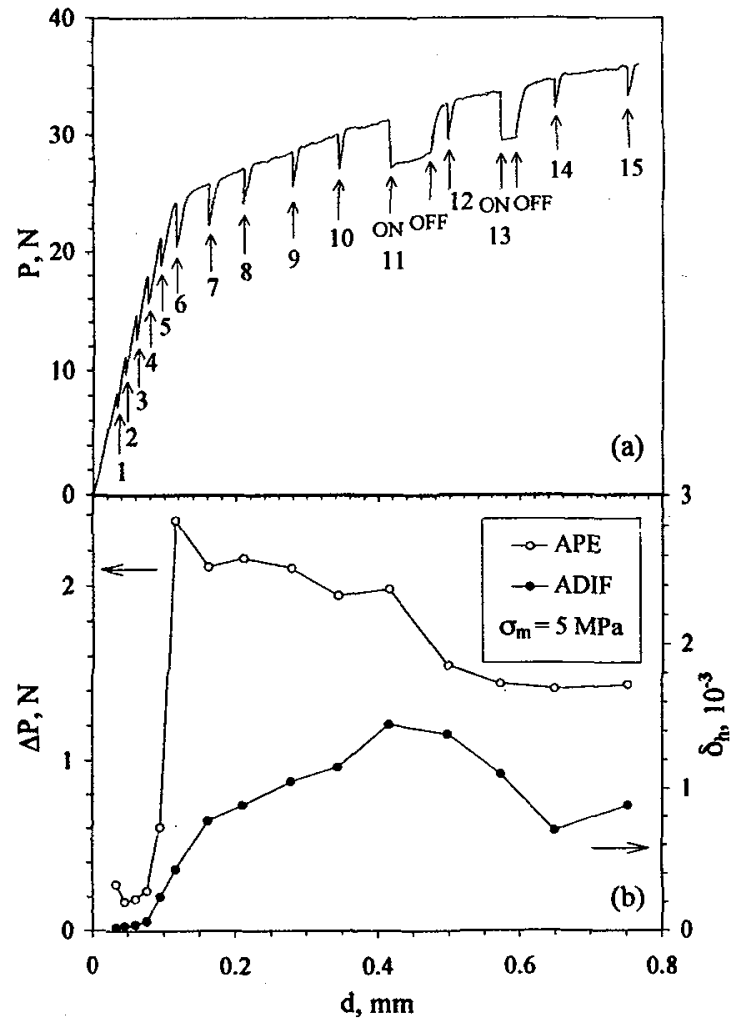

Figure 1: Deformation curve: applied load $P$ vs sag d (a), amplitude-dependent decrement $\delta_{h}$ of an $\mathrm{Al}$ sample and magnitude of the acoustoplastic effect $\Delta P$ for this sample at fixed level of oscillatory stress amplitude $\sigma_{m}=5 \mathrm{MPa}$ during three-point bending of the sample (b). The arrows show the applied load drops due to measurements of stress amplitude dependences.

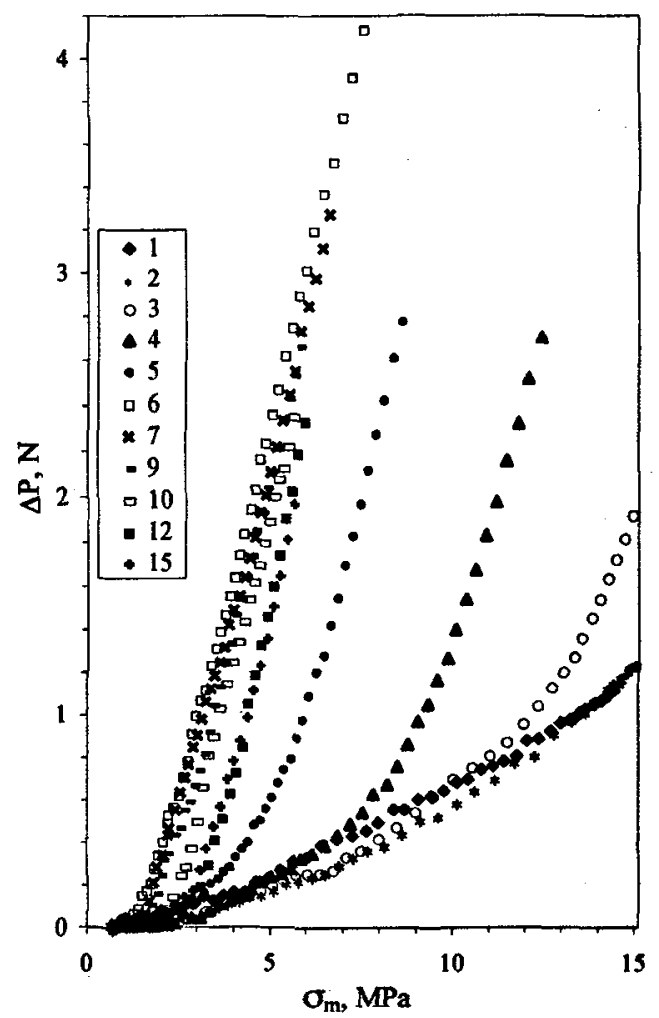

Figure 2: Stress amplitude dependences of the acoustoplastic effect magnitude $\Delta \mathbf{P}$ at different deformation stages. The curves are numbered according to fig. 1 (a). Crosshead movement rate was $10^{-6} \mathrm{~mm} / \mathrm{s}$. 


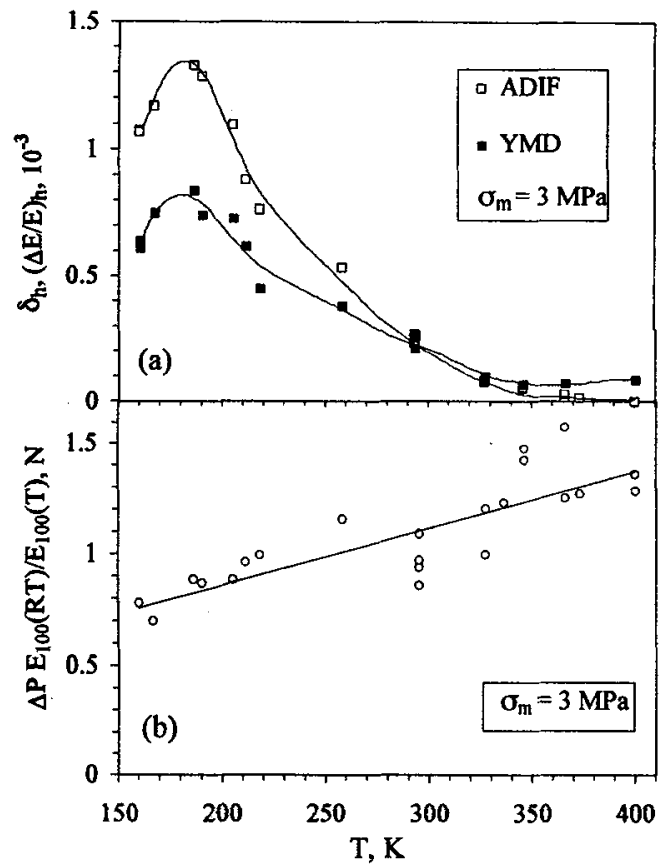

Figure 3: Amplitude-dependent decrement $\delta_{\mathrm{h}}$, Young's modulus defect $(\Delta \mathrm{E} / \mathrm{E})_{\mathrm{h}}(\mathrm{a})$, and acoustoplastic effect $\Delta \mathrm{P} \mathrm{E}_{100}(\mathrm{RT}) / \mathrm{E}_{100}(\mathrm{~T})$ (b) for an $\mathrm{Al}$ sample vs temperature at fixed level of oscillatory stress amplitude $\sigma_{m}=3 \mathrm{MPa}$. The acoustoplastic effect data are approximated by the linear dependence. Crosshead movement rate was $10^{-5} \mathrm{~mm} / \mathrm{s}$.

Figure 4: Stress amplitude dependences of decrement $\delta$ (a), acoustoplastic effect magnitude $\Delta P(b)$, and amplitudedependent decrement $\delta_{h}$ at forward runs (c) measured simultaneously during three-point bending of an Al sample at different crosshead movement rates, $\mathrm{mm} / \mathrm{s}: 1-10^{-3} ; 2-10^{-4}$; $3-10^{-5} ; 4-10^{-6}$.
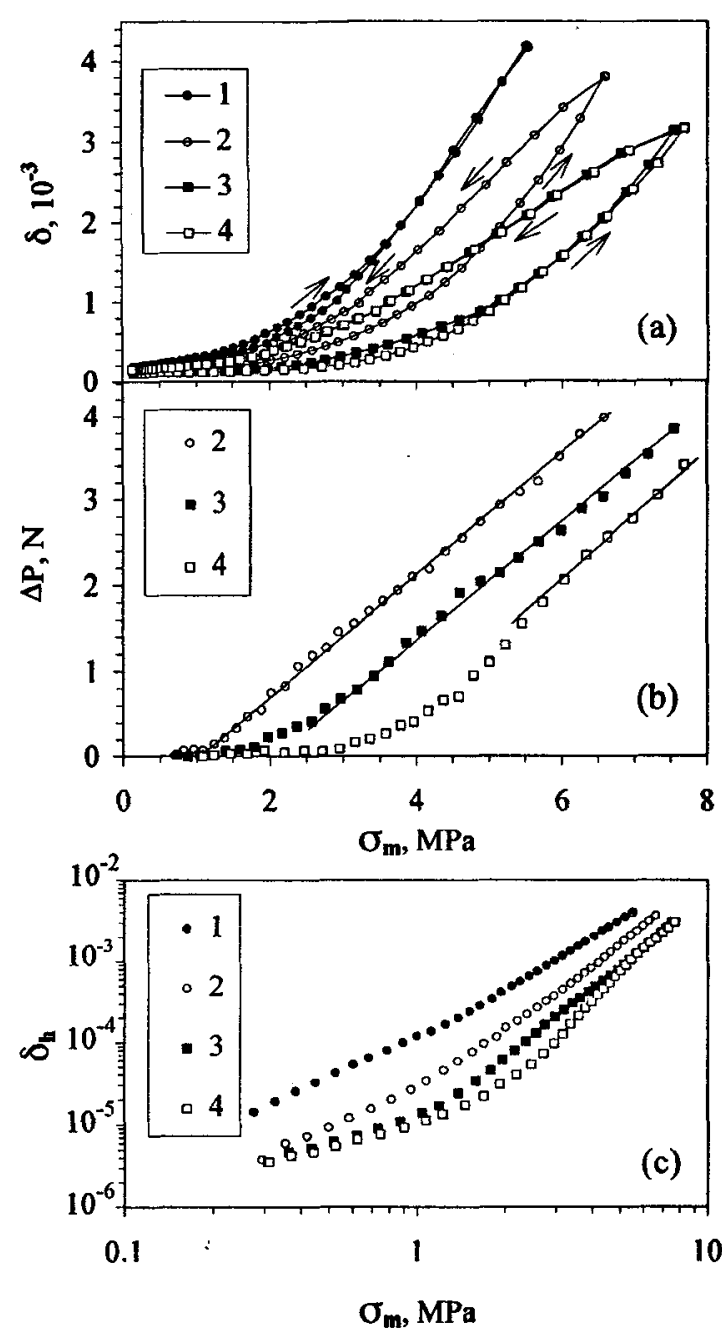

Figure 3 displays temperature dependences of the APE and ADIF magnitudes at fixed $\sigma_{m}$ level. The higher is the temperature the higher is the APE magnitude in the investigated temperature range. The ADIF shows a maximum at temperatures around $180 \mathrm{~K}$. Amplitude hysteresis of the ADIF was observed at temperatures $\mathrm{T}>180 \mathrm{~K}$. Radically different temperature trend of the APE and ADIF argues for a distinction in their basic mechanisms. The ADIF behaviour at $T>180 \mathrm{~K}$ is increasingly controlled by dynamic strain ageing, whereas the APE is considerably less sensitive to this process [4].

Strain rate dependence of the APE and ADIF is demonstrated in Fig.4. The higher is the crosshead movement rate the larger are both APE and ADIF magnitudes and the less pronounced is amplitude hysteresis of the ADIF (it is even reversed at the highest rate). However, the variation of the crosshead movement rate does not affect appreciably the slope of the APE stress amplitude dependence at high amplitudes, influencing the APE threshold stress amplitude only. This is an effect of the dynamic strain ageing [4]. The amplitude dependence of the ADIF is two-staged (see Fig.4(c)). The APE threshold amplitude coincides well with the stress amplitude corresponded to the transition from low-amplitude ADIF stage to the high-amplitude one. This fact may be attributed to the escape of mobile dislocations from impurity Cottrell's atmospheres with the onset of the APE. The first ADIF stage corresponds to oscillatory dislocation movement within the atmospheres. 

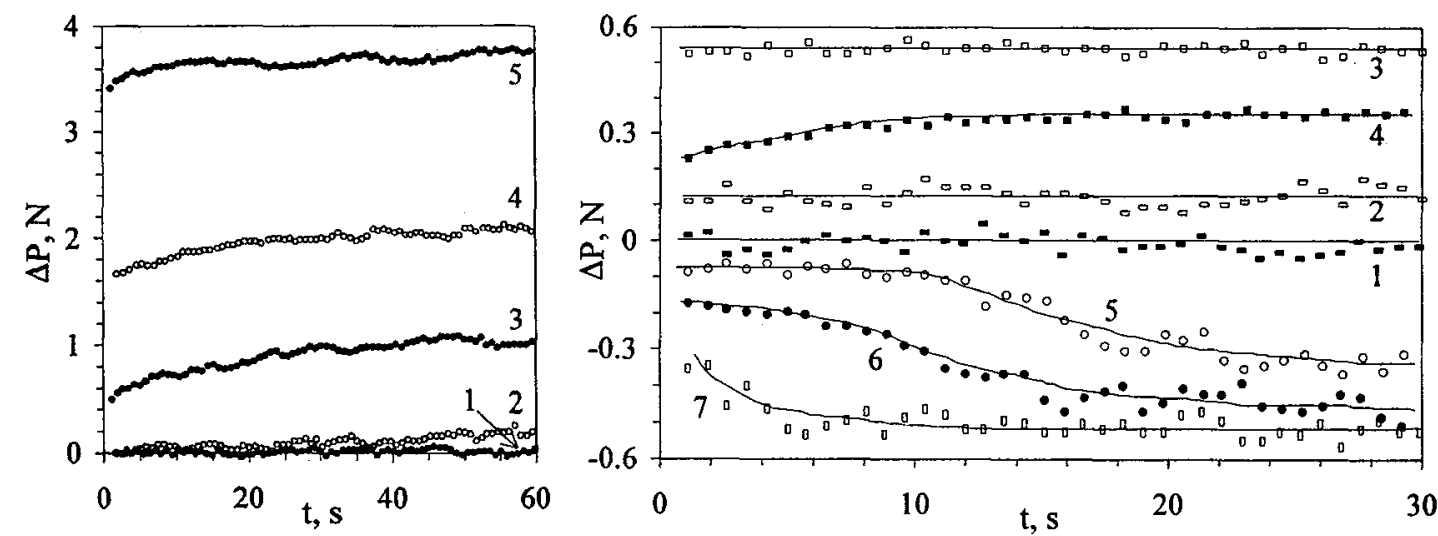

Figure 5: Time dependences of the Figure 6: Time dependences of the acoustoplastic effect magnitude $\Delta P$ in acoustoplastic effect magnitude $\Delta \mathrm{P}$ in microplastic range on loading (curves 1-4) and unloading (curves 5-7) at different macroplastic range at different fixed levels of levels of stress amplitude $\sigma_{\mathrm{m}}$, MPa: $1-3.3 ; 2-4.9 ; 3-8.9 ; 4-3.8 ; 5,6,7-6.5$ and oscillatory stress amplitude $\sigma_{\mathrm{m}}, \mathrm{MPa}: 1-0.6$ 2 - $1.3 ; 3$ - 3.0; 4 - 4.8; 5 - 7.0. Crosshead movement rate was $10^{-5} \mathrm{~mm} / \mathrm{s}$.

different initial values of static load (in the ratio to yield load): $1-0.43 ; 2-0.63$; $3-0.71 ; 4-0.92 ; 5-0.63 ; 6-0.32 ; 7-0.11$. Crosshead movement rate was $10^{-6}$ $\mathrm{mm} / \mathrm{s}$. The negative sign of the effect corresponds to increase in the static load.

Kinetics of the APE at different deformation stages is shown in Figs. 5 and 6. One can see that two distinct APE component exist: 1) "instant" jump of the applied load at the moment of superimposition of the oscillations; 2) gradual long-term variation of the applied load. The second APE component is not observed during loading up to 0.8-0.9 of yield load (see Fig.6, curves 1-4). Threshold stress amplitude of the second APE component appears to be less than that of the "instant" one (see Fig.5, curves 1-3).

\section{CONCLUSIONS}

1. Distinct defect structure levels are responsible for the APE and ADIF. The ADIF is largely due to dislocation - point defect interaction under reversible oscillatory movement of mobile dislocations. The APE is caused by irreversible movement of the same dislocations through long-range internal stress fields of other dislocations and their groups.

2. Dislocation - point defect interaction plays a secondary part in the APE mechanism, even in case of dynamic strain ageing, affecting the APE threshold stress amplitude. The slope of the APE stress amplitude dependence at high amplitudes is determined by dislocation structure only.

3. Dislocations contributing to the APE move under the action of applied static stress less local internal stress in a free-flight-like manner. The sign of the APE on unloading reverses when average internal stress exceeds the applied one, i.e. when strain rate reverses sign.

4. There are two distinct APE components: "fast" (time-independent) and "slow" (time-dependent). The former component is due to the mechanical activation of dislocation movement through internal stress fields during the first cycle of oscillations. The latter component is accumulated during subsequent oscillations owing to dynamic recovery (internal stress relaxation) enhanced by the oscillations.

5. Characteristics of dislocation structure (dislocation density and distribution) should be used as basic parameters of theoretical model of the APE.

\section{References}

[1] Friedrich R., Kaiser G., and Pechhold W., Zs. Metallkunde 60 (1969) 390-398.

[2] Kozlov A.V. and Selitser S.I., Mat. Sci. Eng.A 102 (1988) 143-149.

[3] Tanibayashi M., Phys. Stat. Sol. (a) 128 (1991) 83-94.

[4] Sapozhnikov K.V. and Kustov S.B., Phys. Solid State 37 (1995) 1554-1557; ibid. 38 (1996) 68-71.

[5] Sapozhnikov K.V. and Kustov S.B., Phys. Solid State 38 (1996), in print.

[6] Golyandin S.N., Kustov S.B., Sapozhnikov K.V., Nishino Y., and Asano S., this conference.

[7] Antonov P.I. and Nikanorov S.P., J. Cryst. Growth 50 (1980) 3-7.

[8] Timoshenko S.P. and Gere J.M., Mechanics of materials (Van Nostrand Reinhold Co., N.Y., 1972). 